\title{
Diagnostic Value of Adropin Levels in Acute Pulmonary Embolism Patients
}

\author{
(D) Mustafa Kürșat Ayrancı ${ }^{1}$, (1) Mehmet Gül ${ }^{1}$, (1) Leyla Öztürk Sönmez², (1) Fatma Hümeyra Yerlikaya Aydemir ${ }^{3}$, \\ (D) Mohamed Refik Medni1
}

1Department of Emergency Medicine, Meram Medical Faculty, Necmettin Erbakan University, Konya, Turkey

2Department of Physiology, Selçuklu Medical Faculty, Selçuk University, Konya, Turkey

${ }^{3}$ Department of Biochemistry, Meram Medical Faculty, Necmettin Erbakan University, Konya, Turkey

\begin{abstract}
Aim: This study aimed to evaluate the relationship between serum adropin levels in patients with acute pulmonary embolism (PE).

Materials and Methods: Patients pre-diagnosed with PE based on computed tomographic pulmonary angiography findings and not fulfilling any of the exclusion criteria were included in the PE group. An identical number of participants with comorbidities similar to those of the PE group were included in the control group. These patientswere selected from those who had been referred to the emergency department and were not considered to have PE based on clinical symptoms and risk scores.

Results: Serum adropin levels were found to be high in the PE group. Although the adropin values were high in the case of all comorbidities, the values significantly elevated only in patients with hypertension, acute ischaemic stroke, and previous history of PE. The adropin values were quite different among the Wells score categories, and the mean adropin levels varied significantly between the PE and control groups.

Conclusion: In this study, the plasma adropin levels were significantly high in patients with acute PE and exhibited high positive predictivity, sensitivity, and specificity in detecting PE.
\end{abstract}

Keywords: Adropin, atherothrombosis, endothelial function, pulmonary embolism

\section{Introduction}

Currently, pulmonary embolism (PE) is the most common cardiovascular disease following acute ischemic diseases and stroke. The disease was described by Laennec in 1819, and the association between deep vein thrombosis and PE was firstly demostrated by Virchow in 1846 (1).

In 1856, Virchow identified three factors leading to intravascular coagulation. These factors are stasis, hypercoagulability and vascular endothelial damage. The activation of endothelial cells causes thrombus formation by activating the coagulation system or inhibition of the anticoagulant mechanism $(2,3)$.

Vascular obstruction and increase of resistance are insufficient to explain the pathophysiology of PE alone. Hypoxia and ischemia, neurotrophil activation, release of free oxygen radicals and increased pulmonary artery pressure have destructive effects on endothelium (4).

Endothelium plays a significant role in maintaining vascular circulation. It contributes to the development and progression of inflammatory, metabolic and infectious diseases on the basis of atherothrombosis which has developed due to the disrupted endothelium (5).

Endothelial cells play a role in various physiological and pathological events that affect blood flow and blood pressure by regulating coagulation, fibrinolysis and vascular tonus by its mediators (6).

Endothelial dysfunction has been associated with risk factors of acute vascular events such as hypertension (HT), coronary artery disease (CAD), HF, chronic renal failure, diabetes mellitus (DM) 
and obesity. Endothelial dysfunction is not only the first step of the atherosclerotic process by causing plaque formation, but also causes the plaque to grow, rupture and trigger thrombogenic events (7).

The concentration of adropin in the circulation is regulated by energy intake. Its release is regulated by energy status and dietary nutrient contents (8).

It has been reported that atropine has functions in liver sinusoidal cells, brain vascular cells - neuroglial cells and neurons, cerebellum vascular cells - purkinje cells and neuroglial cells, endocardial myocardial and epicardial tissue in the heart (9).

PE is a clinical condition which is difficult to diagnose, with high morbidity and mortality rates. Levels of D-dimer, cardiac Troponin T and I (CTnT, I), brain natriuretic peptide (BNP) and $\mathrm{N}$-terminal pro-brain natriuretic peptide (NT-proBNP) in blood are traditionally studied in patients suspected to have PE (1012). Although these parameters may indicate the level of fibrin degradation products and cardiovascular dysfunction, they are not enough to provide a certain diagnosis of PE. Thus, new parameters to make a diagnosis of PE more easily and rapidly are required.

Adropin is a recently discovered protein which is considered to be related to endothelial function regulation, thus it is claimed to be an endothelial dysfunction marker $(9,13,14)$.

According to recent studies, adropin may be related to endothelial dysfunction that indicates atherothrombotic changes, especially in DM, acute coronary sydrome (ACS), heart failure (HF), stable CAD and acute ischemic stroke (AIS). In our study, we investigated the relation between adropin levels and PE that may occur based on the endothelium-related atherothrombosis. Also, when the literature was examined, we could not find a study that analysed the relation between adropin and acute PE.

The aim of this prospective study is to evaluate the relation between serum adropin levels and PE diagnosis in acute PE patients.

\section{Materials and Methods}

Consent was taken from Necmettin Erbakan University Meram Faculty of Medicine Ethics Board before the study (decision date/ no: 2016/470). This was a prospective study and informed consent was taken from all patients included in the study. Patients who referred to emergency department between February 2016 and October 2016, examined with PE pre-diagnosis, did not have exclusion criteria and received certain diagnosis via computed tomography pulmonary angiography (CTPA) were included as
PE group. The same number of participants with comorbidities similar to the PE group, but not considered to have PE diagnosis from their clinical symptom and risk scorings were selected as the control group. The flow chart describing the group content is shown in Figure 1.

\section{Exclusion Criteria}

We excluded patients with trauma, those under 18 years of age, the pregnant and those who did not accept to participate in the study.

\section{Study Protocol}

Demographic characteristics, comorbidity conditions and PE major risk factors were noted for the patients included in the study across groups. Results of laboratory tests and the examinations used for imaging, demographic data, blood pressure, heart rate, body temperature, respiratory rate and physical examination were also recorded.

Well's and Revised Geneva Risk Scorings were used for clinical probability determination in patients suspected to have acute PE. Transthoracic echocardiography (ECHO) was performed by a cardiologist in all patients suspected to have acute PE. Considering the clinical probability scores, multi-slice CTPA was ordered to make a certain diagnosis in patients who had no contraindication for contrast enhanced CTPA. Patients who were diagnosed as PE via CTPA and did not have exclusion criteria were included in the study as the PE group.

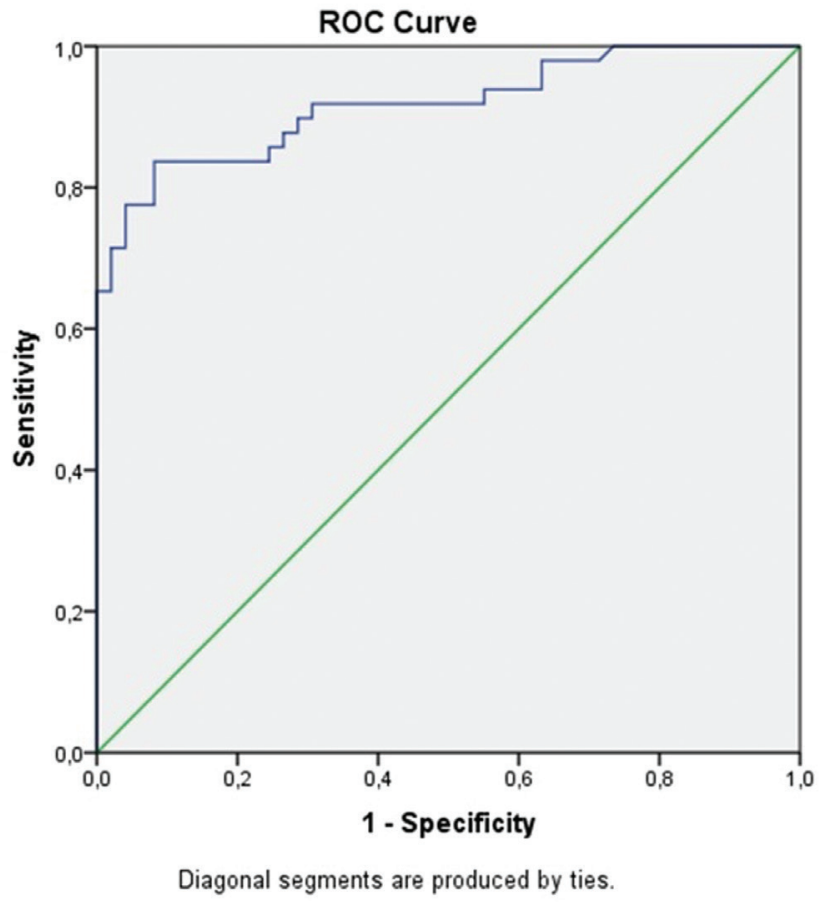

Figure 1. Flow chart describing group contents

ROC: Receiver operating characteristic 
Patients randomly selected among individuals with similar age and comorbidities to the PE group and not considered to have PE diagnosis according to the clinical and risk scorings were determined as the control group. Patients were followedup during hospitalization and any hospital mortalities were registered.

From the blood samples taken for routine blood tests of the patients, routine biochemical, hematological analyses and urine analyses results were obtained. Hematological analyses were performed using XN-1000 Sysmex hematology analyzer. All biochemical parameters were analyzed with kits manufactured for use with Architect c16000 Auto-Analyzer.

From the patients included in the study, intravenous blood samples were also taken to examine adropin levels on referral. Blood serum samples were centrifuged at $4000 \mathrm{rev} / \mathrm{min}$ for 10 minutes in a cooling centrifuge device (HR 46R) and the serums were separated. The separated serum samples were secured in a freezer at $-80^{\circ} \mathrm{C}$. In serum samples; Human adropin levels were analyzed using human adropin ELISA kit via ELISA method in the biochemistry laboratory by a biochemistry specialist.

\section{Statistical Analysis}

Data set analyses were made using SPSS 19.0 program. Continuous variables were presented as median (25-75\%). Categorical variables were given as frequencies and percentages. Normality of distribution of constant numeric variables was made using the Kolmogorov-Smirnov test. The Mann-Whitney U test was used for analyzing two independent groups. Spearman's rho correlation was used to detect the relation between numerical variables and Monte Carlo corrected chi-square analysis was used to detect the relation between categorical variables. A p value was accepted as statistically significant $(\boldsymbol{p}<0.05)$.

\section{Results}

A total of 98 patients including 49 patients in PE group who had a final diagnosis and 49 patients in the control group who were not diagnosed with PE were included. While no difference was observed in age, gender and total comorbidity among PE and control groups included in the study $(p=0.96, p=0.54, p=1$, respectively), a history of previous $\mathrm{PE}$ was found significantly high in PE group ( $p=0.022)$. Details on demographic, comorbidity and laboratory variables are given in Table 1.

Serum adropin levels were found notably high in PE group $(p<0.001)$. While serum adropin level was $273.2(214.4-411.0) \mathrm{ng} /$ $\mathrm{dL}$ in the PE group, it was measured as $135.6(91.2-173.6) \mathrm{ng} / \mathrm{dL}$ in the control group.
Table 1. Numeric values of demographical, comorbidity and laboratory parameters

\begin{tabular}{|l|l|l|l|}
\hline & PE group (n=49) & Control group (n=49) & p \\
\hline \multicolumn{2}{|l|}{ Demographical parameters } & $66(52-77)$ & 0.963 \\
\hline $\begin{array}{l}\text { Age [median } \\
(25-75 \%)\end{array}$ & $67(47.5-81)$ & $23(46.9) / 26(53.1)$ & 0.547 \\
\hline $\begin{array}{l}\text { Gender, } \\
\text { ( \%) } \\
\text { (female/male) }\end{array}$ & $26(53.1) / 23(46.9)$ & $35(71.4)$ & 1.000 \\
\hline $\begin{array}{l}\text { Comorbidity, } \\
\mathrm{n}(\%)\end{array}$ & $35(71.4)$ & $8(16.3)$ & 0.221 \\
\hline $\begin{array}{l}\text { Malignancy, } \\
\mathrm{n}(\%)\end{array}$ & $13(26.5)$ & $18(36.7)$ & 0.156 \\
\hline $\begin{array}{l}\text { Hypertension, } \\
\mathrm{n}(\%)\end{array}$ & $25(51)$ & $13(26.5)$ & 1.000 \\
\hline CAD, n (\%) & $13(26.5)$ & $15(30.6)$ & 0.500 \\
\hline DM, n (\%) & $12(24.5)$ & $3(6.1)$ & 0.111 \\
\hline AIS, n (\%) & $8(16.3)$ & $0(0)$ & $\mathbf{0 . 0 2 2}$ \\
\hline $\begin{array}{l}\text { Past History } \\
\text { of PE, n (\%) }\end{array}$ & $5(10.2)$ &
\end{tabular}

Laboratory parameters [median (25-75)]

\begin{tabular}{|c|c|c|c|}
\hline $\begin{array}{l}\text { Adropin } \\
\text { (ng/dL) }\end{array}$ & $273.2(214.4-411.0)$ & $135.6(91.2-173.6)$ & $<0.001$ \\
\hline WBC $\left(10^{3} / \mathrm{uL}\right)$ & $10.40(7.95-13.20)$ & $8.80(7.10-10.35)$ & 0.030 \\
\hline $\begin{array}{l}\text { Neutrophil } \\
\left(10^{3} / \mathrm{uL}\right)\end{array}$ & $7.50(5.85-10.05)$ & $5.90(4.25-8.00)$ & 0.014 \\
\hline $\begin{array}{l}\text { Lymphocyte } \\
\left(10^{3} / \mathrm{uL}\right)\end{array}$ & $1.50(1.10-2.25)$ & $1.60(1.00-2.30)$ & 0.884 \\
\hline $\begin{array}{l}\text { Neutrophil/ } \\
\text { Lymphocyte } \\
\text { ratio }\end{array}$ & $4.81(3.37-7.85)$ & $3.40(2.00-8.73)$ & 0.140 \\
\hline $\operatorname{RBC}\left(10^{6} / \mathrm{uL}\right)$ & $4.60(3.85-5.05)$ & $4.80(4.45-5.25)$ & 0.081 \\
\hline $\begin{array}{l}\text { Haemoglobin } \\
(\mathrm{g} / \mathrm{dL})\end{array}$ & $12.60(10.80-14.70)$ & $14.10(11.85-14.95)$ & 0.179 \\
\hline $\begin{array}{l}\text { Haemotocrit } \\
(\%)\end{array}$ & $37.60(33.60-43.00)$ & $40.90(36.70-44.35)$ & 0.076 \\
\hline $\mathrm{MCV}(\mathrm{fL})$ & $84.20(81.75-89.30)$ & $84.90(79.80-87.05)$ & 0.760 \\
\hline RDW (\%cv) & $14.50(13.40-16.20)$ & $13.50(12.60-15.65)$ & 0.024 \\
\hline $\begin{array}{l}\text { Platelet } \\
\left(10^{3} / \mathrm{uL}\right)\end{array}$ & $221(162-252.5)$ & $244(218-270)$ & 0.019 \\
\hline MPV (fL) & $10.50(9.80-11.25)$ & $9.90(9.50-10.65)$ & 0.011 \\
\hline BUN (mg/dL) & $36.2(27.5-48.6)$ & $34.10(27.85-47.85)$ & 0.714 \\
\hline $\begin{array}{l}\text { Creatine } \\
(\mathrm{mg} / \mathrm{dL})\end{array}$ & $0.79(0.65-0.89)$ & $0.83(0.74-1.05)$ & 0.077 \\
\hline $\begin{array}{l}\text { Sodium } \\
(\mathrm{mmol} / \mathrm{L})\end{array}$ & $136.2(134.8-138.3)$ & $136.6(134.4-137.5)$ & 0.903 \\
\hline $\begin{array}{l}\text { Potassium } \\
(\mathrm{mmol} / \mathrm{L})\end{array}$ & $4.40(4.20-4.75)$ & $4.40(4.15-4.75)$ & 0.792 \\
\hline \multicolumn{4}{|c|}{$\begin{array}{l}\text { CAD: Coronary artery disease, DM: Diabetes mellitus, AIS: Acute ischemic stroke, } \\
\text { PE: Pulmonary embolism, WBC: White blood cell, RBC: Red blood cell, MCV: Mean } \\
\text { corpuscular volume, RDW: Red cell distribution width, MPV: Mean platelet Volume, } \\
\text { BUN: Blood urea nitrogen } \\
\text { Significant values are shown bold, n: Number }\end{array}$} \\
\hline
\end{tabular}


In the analyses of the complete blood count (CBC) and biochemical parameters, while white blood cell, neutrophil, red cell distribution width values were significantly higher in PE group compared to the control group $(p=0.03, p=0.014, p=0.024$, respectively), platelet and mean platelet volume values were detected to be significantly low ( $p=0.019, p=0.011$, respectively). It was detected that there was no difference between other CBC and biochemical parameters between the two groups (Table 1).

Well's and Revised Geneva Average Scorings were also significantly related to $P E(p<0.001, p=0.001$ respectively). Adropin levels were found to have higher at the intermediate level of clinical probability assessment in both scoring systems. Adropin measurements were compared according to gender, comorbidity parameters and clinical scorings in all PE and control group patients $(n=98)$. Although adropin values were high in the presence of all comorbidity conditions, adropin values were measured significantly higher only in patients who had HT, AIS and previous PE ( $p=0.032, p=0.032, p=0.05$ respectively). Adropin values were also notably different according to Well's Scoring groupings $(\boldsymbol{p}<0.001)$ (Table 2$)$.

In the comorbidity-adropin relation analysis made only in the PE group, this difference was not significant although serum adropin levels were found to be higher in patients with malignancy, HT, DM and AIS and low in patients with CAD ( $p=0.602, p=0.258$, $p=0.111, p=0.700, p=0.717$, respectively) (Table 3).

As mean adropin levels were found significantly different among PE and control groups, a test of whether adropin had a distinctive diagnosis character or not was done via ROC analysis. The analysis showed that the ROC curve was rather high and significant $(p<0.001)$ (Figure 2). Adropin cut-off values corresponding to the maximum value for the total of sensitivity and specificity were measured as $196.60 \mathrm{ng} / \mathrm{dL}$. It was also detected that serum adropin levels had $83.6 \%$ sensitivity, $91.3 \%$ specificity in PE diagnosis and false negativity ratio was detected as $16.3 \%$.

\section{Discussion}

Although there are many diagnostic methods today, PE still constitutes a significant diagnosis problem for clinicians. The mortality ratio of the disease can be decreased from $30 \%$ to 2-10\% with early diagnosis and treatment applications $(15,16)$. CTPA and ECHO are diagnosis tools which are not easily accessible for early diagnosis. Studies are being made with many different markers today to reach a faster PE diagnosis. But sensitivity and specificity are not adequate as many markers are disease-related (15-17). Thus, the search for new biomarkers continues.
It is reported that only $30 \%$ of all PE cases are diagnosed and treated in USA (18). Thus, new biochemical markers with high diagnostic accuracy are required. Biomarkers with high diagnostic specificity may provide the clinician with the possibility to early risk classification and start the appropriate treatment.

Adropin, which was discovered for the first time in 2008 by Kumar et al. (13), is a product of the energy homeostasis-associated $(E N H O)$ gene and a peptide-structured hormone containing 42 aminoacid, and is thought to play a role in the regulation of energy homeostasis $(19,20)$. Lower adropin levels are associated with obesity, dyslipidemia, hepatic steatosis, and increased fat mass. Circulating adropin levels were found to be low in DM, gestational DM, metabolic syndrome, non-alcoholic fatty liver disease, polycystic ovary syndrome, and CAD (19-21). In addition, adropin has a protective effect on endothelial functions by enhancing the release of nitric-oxide and activating endothelial nitric oxide (eNOS) (21). Based on the fact that there is endothelium

Table 2. Comparison of adropin levels in PE and control group according to gender, comorbidity and clinical scoring results

\begin{tabular}{|c|c|c|c|}
\hline & & $\begin{array}{l}\text { Adropin value (ng/dL) } \\
\text { [median }(25-75 \%)]\end{array}$ & $\mathbf{p}$ \\
\hline \multirow{2}{*}{ Gender } & Female & $196.0(138.4-263.0)$ & \multirow{2}{*}{0.394} \\
\hline & Male & $168.8(105.0-314.8)$ & \\
\hline \multirow{2}{*}{ Malignancy } & Negative & 180.8 (120.4-261.8) & \multirow{2}{*}{0.408} \\
\hline & Positive & $220.4(127.0-387.8)$ & \\
\hline \multirow{2}{*}{ HT } & Negative & $164.8(112.4-238.0)$ & \multirow{2}{*}{0.032} \\
\hline & Positive & $218.0(148.8-286.0)$ & \\
\hline \multirow{2}{*}{ CAD } & Negative & 168.4 (112.8-278.5) & \multirow{2}{*}{0.138} \\
\hline & Positive & $209.0(164.2-268.4)$ & \\
\hline \multirow{2}{*}{ DM } & Negative & $190.4(128.4-273.2)$ & \multirow{2}{*}{0.978} \\
\hline & Positive & $178.4(109.2-279.2)$ & \\
\hline \multirow{2}{*}{ AIS } & Negative & $178.4(119.6-264.0)$ & \multirow{2}{*}{0.032} \\
\hline & Positive & $259.6(203.6-411.2)$ & \\
\hline \multirow{2}{*}{ PE } & Negative & $180.8(120.4-270.0)$ & \multirow{2}{*}{0.05} \\
\hline & Positive & $264.0(209.6-571.2)$ & \\
\hline \multirow{3}{*}{ Well's score } & Low & $150.0(103.4-212.5)$ & \multirow{3}{*}{$<0.001$} \\
\hline & Mean & $268.6(211.4-400.2)$ & \\
\hline & High & $212.4(137.5-643.0)$ & \\
\hline \multirow{3}{*}{$\begin{array}{l}\text { Revised } \\
\text { Geneva score }\end{array}$} & Low & $151.6(90.4-215.8)$ & \multirow{3}{*}{0.094} \\
\hline & Mean & $199.2(135.9-280.9)$ & \\
\hline & High & $183.6(124.4-505.7)$ & \\
\hline
\end{tabular}



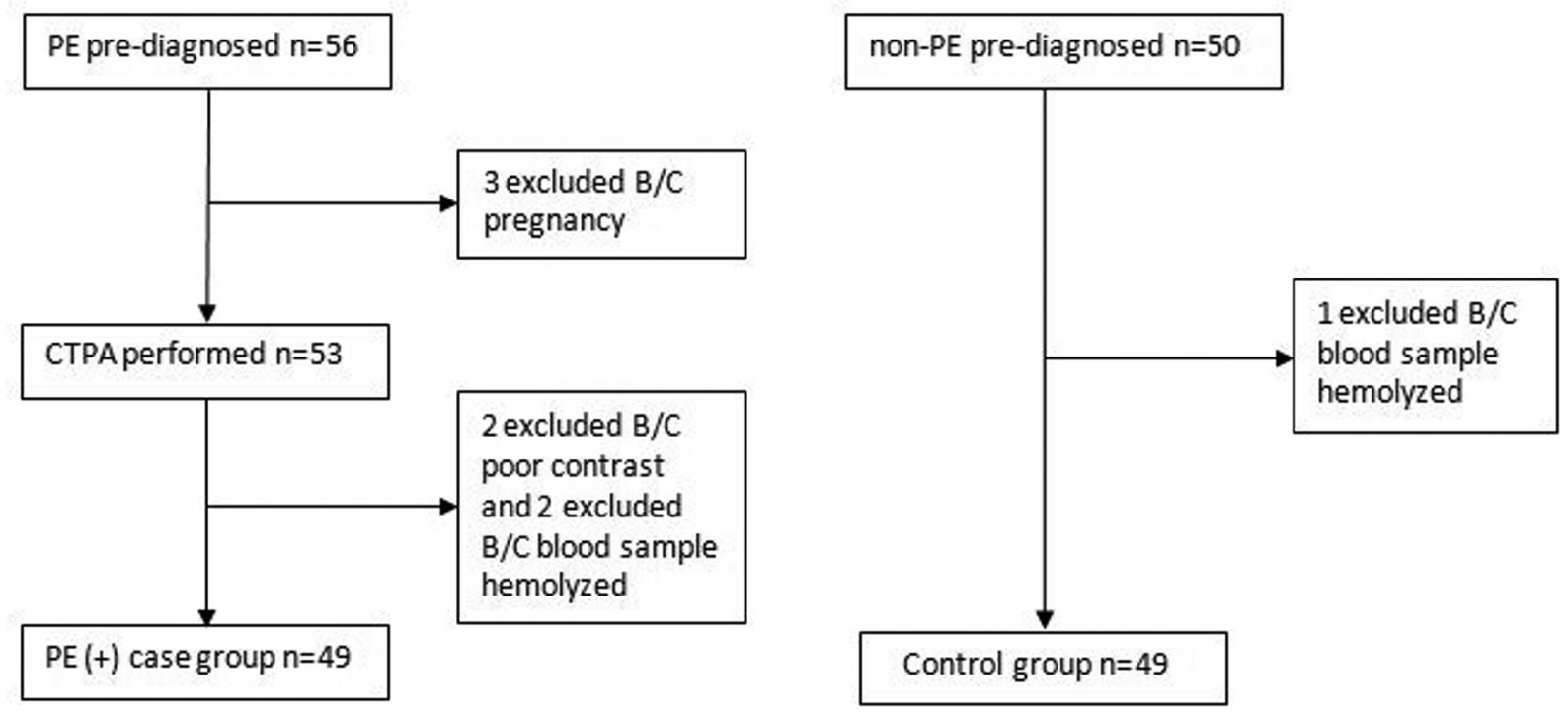

Figure 2. ROC curves of adropin in PE and control group

ROC: Receiver operating characteristic, PE: Pulmonary embolism, CTPA: Computed tomography pulmonary angiography, BUN: Blood urea nitrogen, B/C: BUN/Creatinine ratio, n: Number

\begin{tabular}{|c|c|c|c|}
\hline & & $\begin{array}{l}\text { Adropin value }(\mathrm{ng} / \mathrm{dL}) \\
\text { [median }(25-75 \%)]\end{array}$ & $p$ \\
\hline \multirow{2}{*}{ Malignancy } & Negative $(n=36)$ & $265.4(214.4-411.1)$ & \multirow{2}{*}{0.602} \\
\hline & Positive ( $n=13$ ) & 350.4 (210.8-409.6) & \\
\hline \multirow{2}{*}{ HT } & Negative $(n=24)$ & $242.6(169.1-565.2)$ & \multirow{2}{*}{0.258} \\
\hline & Positive $(n=25)$ & $279.2(251.4-408.8)$ & \\
\hline \multirow{2}{*}{ CAD } & Negative $(n=36)$ & $277.8(201.5-411.0)$ & \multirow{2}{*}{0.717} \\
\hline & Positive $(n=13)$ & $266.8(234.0-411.0)$ & \\
\hline \multirow{2}{*}{ DM } & Negative $(n=37)$ & $259.6(201.8-393.2)$ & \multirow{2}{*}{0.111} \\
\hline & Positive $(n=12)$ & $345.0(231.3-748.7)$ & \\
\hline \multirow{2}{*}{ AIS } & Negative $(n=41)$ & 266.8 (208.4-408.8) & \multirow{2}{*}{0.700} \\
\hline & Positive $(n=8)$ & $281.2(225.7-425.9)$ & \\
\hline
\end{tabular}

HT: Hypertension, CAD: Coronary artery disease, DM: Diabetes mellitus, AIS: Acute ischemic stroke, PE: Pulmonary embolism

damage in the pathogenesis of PE and the consequent relation between adropin and PE, our study aimed to examine the effect, sensitivity and specificity of adropin as a diagnostic tool for PE.

Marczuk et al. (22) investigated the physiological and pathophysiological role of adropin and stated that release and regulation of adropin was controversial and adropin was detected in brain, cerebellum, liver, kidney, heart, pancreas, small intestine, endothelial cells, colostrum, milk and other different tissues and body fluids. Detection of adropin in endothelial cells makes us consider that adropin would have a significant effect on endothelial function. Adropin is considered to be related to endothelium function regulation $(9,13)$. Topuz et al. (9) claimed that adropin could be a marker for endothelial dysfunction.
Lovren et al. (19) claimed that adropin is released from umblical vein and coronary artery endothelial cells and regulated eNOS and adropin is a potential preserver.

Wenlin et al. (20) showed that the adropin levels were directly proportional with HF severity in HF patients. Wu et al. (8) stated that circulating low adropin levels were closely related to coronary atherosclerosis occurrence in diabetic and nondiabetic coronary atherosclerosis patients and could be regarded as an atherosclerosis marker. Aydin et al. (23) claimed that adropin was released in the blood after cardiac muscle cell damage. It has been shown that adropin is released into the bloodstream during myocardial muscle injury caused by myocardial infarction, and serum adropin levels increase as myocytes die.

It was also reported that serum adropin levels could be a potential marker for diagnosis in acute coronary syndrome patients. It has been shown that adropin increases with other cardiac markers and adropin begins to decrease at 4 hours earlier than other markers, in enzyme positive acute coronary syndrome (24). Based on the results of our study, we think that adropin will increase in cases such as atherosclerosis and atherothrombosis in order to protect the endothelium.

For the pathogenesis, an increasing number of proofs state that adropin is a strong regulator for cardiovascular functions (25). Gu et al. (26) stated that adropin is an independent marker for HT and can influence blood pressure by preserving endothelial function. Zhao et al. (27) stated that low serum adropin levels are a significant marker for stable CAD. Supporting the literature, 
adropin values in the PE group were found lower in patients who had CAD before.

Serum adropin levels were significantly lower in DM patients compared to non-diabetic patients, and conversely, they were independently associated with angiographic severity of coronary atherosclerosis (8). In our study, when all DM patients in the case and control groups were considered, adropin levels were found to be high in DM patients. In our study, in our control group without PE; Adropin levels were found $125.6 \mathrm{ng} / \mathrm{dL}$ (79.6-160.0) and 139.6 $\mathrm{ng} / \mathrm{dL}$ (92.6-181.5) in DM patients $(\mathrm{n}=15)$ and in patients without DM $(n=34)$, respectively. Consistent with literature data, adropin levels were found low in DM patients without PE.

There have been many studies about other biomarkers in PE diagnoses. Kelly et al. (28) and Brown et al. (29) found D-dimer test to have a high sensitivity but a low specifity. Elevated serum troponin levels indicate right ventricle dysfunction (30). High BNP levels are reported to be related with right ventricle dysfunction and early mortality $(31,32)$.

For prognostic purposes, troponin, BNP and NT-proBNP tests may be useful to distinguish massive and submassive PE from nonmassive. But, it should be kept in mind that these markers are also high in chronic obstructive pulmonary disease attack, sepsis, acute renal failure, trauma, rhabdomyolysis and congestive HF (33).

Adropin positive predictivity, sensitivity and specificity were detected to be significantly high in the examination. These parameters allow us to note that adropin can be a useful biomarker for PE diagnosis. Based on these measurements, we also think that more attention should be paid to PE prediagnosed patients who have adropin values over $196.60 \mathrm{ng} /$ dL cut-off value. Similarly, the cut-off values of adropin in ACS, Cardiac syndrome X and STEMI patients were found to be $412 \mathrm{ng} /$ dL, $273 \mathrm{ng} / \mathrm{dL}, 275.9 \mathrm{ng} / \mathrm{dL}$, respectively $(24,34,35)$.

Due to all these findings mentioned above and considering the literature studies, we think that adropin levels can be a diagnostic biochemical marker for PE and more comprehensive studies on this subject are required.

\section{Study Limitations}

Our study is a cross-sectional study with relatively small sample size. The low number of patients, the low number of isolated PE patients due to additional comorbidities of the patients, lack of adropin tests for post-PE treatment can be counted as the limitations of our study. Since additional diseases of the patients in the study population also affect adropin levels, they may contribute negatively to the results of our study.

\section{Conclusion}

Plasma adropin levels were found significantly high in acute PE patients in our study and had high positive predictivity, sensitivity and specificity. Based on these data, adropin can be a significant biochemical marker for the diagnosis of acute PE patients. We believe that a decrease in mortality, morbidity and avoidance of unnecessary health expenses can be achieved if more comprehensive biomarker studies such as adropin are supported to achieverapid diagnosis in acute PE and fast access to treatment. Therefore, our results should be confirmed by multicenter prospective studies and animal experiments in patients with definitive PE diagnosis who do not have concomitant diseases affecting adropin levels such as ACS, CAD, HF, Malignancy, HT, DM, AIS with larger sample size.

In addition, studies on levels of adropin for a single clinical condition should be also performed in cases of hypoxic conditions and endothelial damage.

\section{Ethics}

Ethics Committee Approval: Consent was taken from Necmettin Erbakan University Meram Faculty of Medicine Ethics Board before the study (decision date/no: 2016/470).

Informed Consent: This was a prospective study and informed consent was taken from all patients included in the study.

Peer-review: Externally peer-reviewed.

\section{Authorship Contributions}

Surgical and Medical Practices: M.K.A., M.G., F.H.Y.A., Concept: M.K.A., M.G., L.Ö.S., Design: M.K.A., M.G., L.Ö.S., M.R.M., Data Collection or Processing: M.K.A., M.G., Analysis or Interpretation: M.K.A., M.G., F.H.Y.A., Literature Search: M.K.A., L.Ö.S., Writing: M.K.A., L.Ö.S., M.R.M.

Conflict of Interest: No conflict of interest was declared by the authors.

Financial Disclosure: The authors declared that this study received no financial support.

\section{References}

1. Smith TP. Pulmonary embolism; what's wrong with this diagnosis? AJR. 2000;174:1489-97.

2. Guyton AC, Hall JE. Tıbbi Fizyoloji. In: Yüce Yayıncılık, İstanbul, Çavuşoğlu HN, Yeğen BC, Aydın Z, Alican I, editors. 9. Baskı; 1996;463-9.

3. Riedel M. Venous Tromboembolic Disease, Acute Pulmonary Embolism, Pathophysiology, Clinical Presentation and Diagnosis. Heart. 2001;85:229 40

4. Stratmann G, Gregory GA. Neurogenic and humoral vasoconstriction in acute pulmonary thromboembolism Anesth Analg. 2003;97:341-54.

5. Verma S, Buchanan MR, Anderson TJ. Endothelial function testing as a biomarker of vascular disease. Circulation. 2003;108:2054-9. 
6. Endemenn DH, Schriffrin EL. Endothelial dysfunction. J Am Soc Nephrol. 2004;15:1983-92.

7. Roquer J, Segura T, Serena J, Castillo J. Endothelial dysfunction, vascular disease and stroke: the ARTICO study. Cerebrovasc Dis. 2009;27(Suppl 1):2537.

8. Wu L, Fang J, Chen L, Zhao Z, Luo Y, Lin C, et al. Low serum adropin is associated with coronary atherosclerosis in type 2 diabetic and non-diabetic patients. Clin Chem Lab Med. 2014;52:751-8.

9. Topuz M, Celik A, Aslantas T, Demir AK, Aydin S, Aydin S. Plasma adropin levels predict endothelial dysfunction like flow-mediated dilatation in patients with type 2 diabetes mellitus. J Investig Med. 2013;61:1161-4.

10. Di Nisio M, Squizzato A, Rutjes AWS, Büller HR, Zwinderman AH, Bossuyt PMM. Diagnostic accuracy of D-dimer test for exclusion of venous thromboembolism: a systematic review. J Thromb Haemost 2007;5:296-304.

11. Giannitsis E, Müler-Bardoff M, Kurowski V, Weidtmann B, Wiegand U, Kampmann M, et al. Independent prognostic value of cardiac troponin $\mathrm{T}$ in patients with confirmed pulmonary embolism. Circulation. 2000;102;211-7.

12. Stein BC, Levine RI. Natriuretic peptides: Physiology, therapeutic potential, and risk stratification in ishemic heart disease. Am Heart J. 1998;135:914-23.

13. Kumar KG, Trevaskis JL, Lam DD, Sutton GM, Koza RA, Chouljenko VN, et al. Identification of adropin as a secreted factor linking dietary macronutrient intake with energy homeostasis and lipid metabolism. Cell Metab. 2008;8:468-81.

14. Kumar KG, Zhang J, Gao S, Rossi J, Mc Guinness OP, Halem HH, et al. Adropin deficiency is associated with increased adiposity and insulin resistance. Obesity (Silver Spring). 2012;20:1394-402.

15. Konstantinides SV, Torbicki A, Agnelli G, Danchin N, Fitzmaurice D, Galiè N, et al. 2014 ESC Guidelines on the diagnosis and management of acute pulmonary embolism: The Task Force for the Diagnosis and Management of Acute Pulmonary Embolism of the European Society of Cardiology (ESC) Endorsed by the European Respiratory Society (ERS). Eur Heart J. 2014;35:3033-69.

16. Merli G]. Pulmonary Embolism in 2017: How We Got Here and Where Are We Going? Tech Vasc Interv Radiol. 2017;20:128-34.

17. Cohen DM, Winter M, Lindenauer PK, Walkey AJ. Echocardiogram in the Evaluation of Hemodynamically Stable Acute Pulmonary Embolism: National Practices and Clinical Outcomes. Ann Am Thorac Soc. 2018;15:581-8.

18. Morgenthaler TI, Ryu JH. Clinical characteristics of fatal pulmonary embolism in a referral hospital. Mayo Clin Proc. 1995;70:417-24

19. Lovren F, Pan Y, Quan A, Singh KK, Shukla PC, Gupta M, et al. Adropin is a novel regulator of endothelial function. Circulation. 2010;122(Suppl):S185-92.

20. Wenlin L, Xiaosong G, Yongwen Q, Xing Z. Elevated Plasma Levels of Adropin in Heart Failure Patients. Intern Med. 2011;50:1523-7.
21. Inal ZO, Erdem S, Gederet Y, Duran C, Kucukaydin Z, Kurku H, et al. The impact of serum adropin and ischemia modified albumin levels based on BMI in PCOS. Endokrynol Pol. 2018;69:135-41.

22. Marczuk N, Cecerska-Heryc E, Jesionowska A, Dolegowska B. Adropin physiological and pathophysiological role. Postepy Hig Med Dosw. 2016;70:981-8.

23. Aydin S, Kuloglu T, Aydin S, Kalayci M, Yilmaz M, Çakmak T, et al. Elevated adropin: a candidate diagnostic marker for myocardial infarction in conjunction with troponin-I. Peptides. 2014;58:91-7. [Epub 2014 Jun 14].

24. Aydin S, Eren MN, Yilmaz M, Yardim M, Aydin S, Kalayci M, et al. Adropin as a potential marker of enzyme-positive acute coronary syndrome. Cardiovasc J Afr. 2017;28:40-7.

25. Li L, Xie W, Zheng XL, Yin WD, Tang CK. A novel peptide adropin in cardiovascular diseases. Clinica Chimica Acta. 2016;453:107-13.

26. Gu X, Li H, Zhu X, Gu H, Chen J, Wang L, et al. Inverse Correlation Between Plasma Adropin and ET-1 Levels in Essential Hypertension: A Cross-Sectional Study. Medicine Baltimore. 2015;94:e1712.

27. Zhao LP, Xu WT, Wang L, You T, Chan SP, Zhao X, et al. Serum adropin level in patients with stable coronary artery disease. Heart, Lungand Circulation. 2015;24:975-9.

28. Kelly J, Rudd A, Lewis RR, Hunt BJ. Plasma D-dimers in the diagnosis of venous thromboembolism. Arch Intern Med. 2002;162:747-56.

29. Brown MD, Rowe BH, Reeves MJ, Bermingham JM, Goldhaber SZ. The accuracy of the enzyme-linked immunosorbent assay D-dimer test in the diagnosis of pulmonary embolism: a meta-analysis. Ann Emerg Med. 2002;40:133-44.

30. Pruszczyk P, Bochowicz A, Torbicki A, Szulc M, Kurzyna M, Fijałkowska A, et al. Cardiac troponin T monitoring identifies high-risk group of normotensive patients with acute pulmonary embolism. Chest. 2003;123:1947-52.

31. Kucher N, Printzen G, Goldhaber SZ. Prognostic role of brain natriuretic peptide in acute pulmonary embolism. Circulation. 2003;107:2545-7.

32. Cavallazi R, Nair A, Vasu T, Marik PE. Natriuretic peptides in acute pulmonary embolism: a systematic review. Int Care Med. 2008;34:2147-56.

33. Lazzeri C, Bonizzoli M, Cianchi G, Gensini GF, Peris A. Troponin-I in the intensive care unit setting: from the heart to the heart. Intern Emerg Med. 2008;3:9-16.

34. Celik A, Balin M, Kobat MA, Erdem K, Baydas A, Bulut M, et al. Deficiency of a New Protein Associated with Cardiac Syndrome X; Called Adropin. Adropin as a potential marker of enzyme-positive acute coronary syndrome. Cardiovasc Ther. 2013;31:174-8.

35. Ertem AG, Ünal S, Efe TH, Açar B, Yayla C, Kuyumcu MS, et al. Association between serum adropin level and burden of coronary artery disease in patients with non-ST elevation myocardial infarction. Anatol J Cardiol. 2017;17:119-24. 